\title{
Cinema e jornalismo: \\ o melodrama e a tragédia moderna
}

$\frac{\text { LISANDRO NOGUEIRA }}{\text { UFG }}$ 


\section{Resumo}

O cinema clássico e o telejornalismo possuem formas de narrar aproximáveis. Eles são semelhantes na busca da "objetividade" e na ênfase ao melodrama e ao espetáculo como eixo de identificação do espectador. Doces Poderes (1996), de Lucia Murat, se situa nessa chave. Um céu de estrelas (1996), da cineasta Tata Amaral, se distancia do melodrama, se aproxima de um sentido de tragédia e critica os procedimentos objetivos do telejornalismo. A análise dos filmes possibilita averiguar como o cinema brasileiro representa o telejornalismo e avalia as proximidades e diferenças entre os dois campos:-

\section{Palavras-chave}

Jornalismo, Cinema, Telejornalismo, Melodrama, Tragédia

\section{Abstract}

Classical cinema and broadcastHU journalism have narrative forms which are similar in that the two of them search for "objectivity" and have melodrama as its central characteristic. The film Doces Poderes (1996), by Lucia Murat, combines these two elements, while Um céu de estrelas (1996), by film director Tata Amaral, deviates from melodrama and criticizes the objective procedures of broadcast journalism. The analysis of these two films allows us to examine how Brazilian cinema represents broadcast journalism and evaluates the similarities and differences between both areas.

\section{Key words}

Cinema and Journalism, Melodrama and Modern Tragedy 


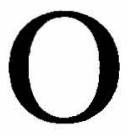

cinema brasileiro tem apresentado filmes, desde os anos 60 , que representam o jornalismo e o jornalista. Esses filmes geralmente utilizam a narrativa clássica do cinema - a mais comum e predominante na cultura ocidental desde o começo do século XX. Essa narrativa tem como base o melodrama canônico oriundo do século IX. Nele, o conteúdo tem prevalência sobre a forma (a linguagem) e os temas emergem buscando a comunicação rápida com o público.

Eficiente e vitoriosa junto ao grande público, essa narrativa clássica, desde o início, elegeu o jornalista como personagem importante. Por seu intermédio, procurou compreender e representar as mudanças operadas nos grandes centros urbanos com o advento do mundo moderno.

Entretanto, essa representação do jornalismo e do jornalista é permeada de contradições e indagações. Sabemos que a imagem do jornalista no século XX foi formada, em boa parte, pelo cinema. São os filmes clássicos que constroem uma imagem superficial do campo e da profissão. Isto porque, elegem um modelo de narrativa que não suporta personagens densos, comunicação também pela forma (não privilegiando somente o tema) e se contenta com o aplauso rápido e domesticado do grande público.

Meu intuito é observar como o cinema brasileiro contemporâneo representa o campo e a profissão. O filme Um céu de estrelas (1996), de Tata Amaral, é nosso objeto. A análise aborda os motivos pelos quais o filme distancia-se do melodrama e aproxima-se do conceito de tragédia (Raymond Wilhams) e, de que maneira, o jornalismo (o telejornalismo) é representado. 
No filme Doces poderes de Lúcia Murat (1996) tem-se uma representação em que a pretensa crítica ao jornalismo esbarra nas próprias armadilhas da narrativa. É o oposto do que ocorre com Um céu de estrelas, da cineasta Tata Amaral. No filme, o telejornalismo ganha um diagnóstico diferente. A escolha do enredo privilegia uma estrutura próxima da tragédia. O filme é baseado na obra do escritor Fernando Bonassi que sintetiza a história desse modo:

Um homem seqüestra sua ex-noiva, pretendendo fazer com ela volte a amá-lo. Um gesto desesperado, sem dúvida. Um gesto suicida? Certamente. Trata-se de uma história simples. Não há grandes revelações na organização de sua narrativa. Tudo que interessa ao romance policial guardar para o final, sabemos desde a primeira página. Mas não era o romance policial que eu estava procurando. Não me interessava o modelo do jogo em que os elementos da trama: vão sendo dosados com uma receita apetitosa. O sabor de Um céu de estrelas é amargo. Os desejos estão à flor da pele, com toda a vitalidade, violência e, para muitos, sujeira. A paisagem não oferece qualquer atrativo: Zona leste, estertorando ante os cadáveres juvenis que decoram as ruas. A situação dos personagens parece não indicar uma.saída. O.desemprego, o abandono, a miséria cotidiana que vai sangrando aos poucos, esvaziando, tirando o sentido de qualquer expectativa. Meu interesse foi documentar. uma trajetória para a desgraça. Lenta, inexorável...essas historias comuns, essa espécie de inércia assassina que se apossa de algumas pessoas e é tão pior num país em que a produção da desesperança é a própria técnica das relações entre os poderosos e os miseráveis (Bonassi, 1999)

Dalva (Alleyona Cavalli) recebe o ex-namorado Vítor (Paulo Vespúcio) em casa. Ela ganhou um concurso de penteados e está de viagem marcada para Miami (EUA). Sua mãe não simpatiza com 
Vítor e o quer longe da filha. $O$ filme apresenta personagens sem referência psicológica ou social. Não se aposta numa explicação dos personagens.

Em Doces poderes, Bia, jornalista de televisão, trava um diálogo com Bob - jornalista que está se transferindo para o marketing político. Neste, as premissas do filme e a biografia dela são apresentadas de forma didática. Em cada diálogo há a intenção da explicação.com o.intuito de instaurar um tipo de pedagogia moral. No melodrama, a explicação das causas e efeitos facilita a identificação do público com os personagens e temas, visto que não há a dramatização necessária para adensar os personagens. Eles necessitam ser didáticos, prontos para serem assimilados, sua trajetória já está claramente especificada na ação porque seus destinados já estão traçados. Daí a ternura do público para com esses personagens. Ternura que se torna gratidão e gratificação. Em seu desamparo diante da tela, sozinho, no escuro, apesar da sala cheia de gente, o espectador sente-se conciliado com a humanidade. A sua submissão ao desejo do personagem, ou ao desejo do outro, conforme a psicanálise, traz a gratificação cativa. É como uma relação amorosa, na:qual se concluí enganosamente que o abandono e a sensação da falta estão definitivamente afastados.

Ou seja, no melodrama o que se espera sempre é a gratificação pelo processo identificatório. Mas quando as histórias são desnudadas e desidentificadas, sobrevêm as surpresas e muitas vezes o desapontamento. É o que acontece quando se vê um filme mais de uma vez. Toda a surpresa, uma das chaves para a identificação, não corresponde mais àquela reposição de afeto garantida pela primeira visada. Daí a puxada de tapete e a desilusão semelhante àquela que acontece com o sujeito quando descobre, no processo analítico, que o "outro" não vai preencher todo o seu vazio existencial.

Bia gratifica o espectador por ser a heroína de uma boa causa, em busca da verdade. $O$ espectador identifica-se com sua vontade de superar obstáculos e enfrentar os perversos. Seu esforço enternece e provoca a familiaridade. Há uma beleza em seu desejo de ser correta e avatar dos bons propósitos. Entretanto, um segundo e terceiro olhar já não garantem o mesmo efeito, pois o sentido da 
identificação é quebrado: Daí a desilusão. Mas poucos vêem um filme mais de uma vez e a possibilidade da corrente apaziguadora quebrar é muito pequena. Ao contrário, ávido por narrativas que preencham o "vazio" e ansioso por afeto, esquecemos da impossibilidade do desejo do outro ocupar o nosso lugar, a nossa falta.

Uì céu de estrelas inverte esse processo. Os personagens são o avesso dópersonagem melodramático. O melodrama se manifesta quando há o confronto entre Vítor e a mãe, e na cobertura da. televisão, quando o telejornalismo invade o espaço privado. A narrativa aponta que eles não têm o controle de suas vidas. $\mathrm{O}$ acaso determina o destino e isso faz com quê cada ação se torne imprevisível e chegue a uma situação extrema:

A idéia de tragédia vê-se então marcada pela impossibilidade de os personagens exercerem um papel de agente dramático, pela carência de poder decisório, pelo seu envolvimento num processo sobre o qual não exercem nenhum controle e que eles não entendem (Bernardet; 1999)

Não sabemos para que lado caminha a história. Os personagens, o ponto de ancoragem do espectador, não facilitam a identificação. A relação de Vítor e Dalva, sem as informações prévias, dificulta esse apoio porque não há muitas explicações, ao contrário de Doces poderes, inundado de explicações totalizantes. Abreu (1999) afirma que "os personagens trágicos encenam o poder, enquanto um personagem melodramático vive uma impossibilidade real".

Daí resulta o mal-estar e o incômodo em.ver os dois em $U m$ céu de estrelas perambulando pela casa sem as explicações a que o público está acostumado no melodrama. Onde tudo aquilo vai parar? $\mathrm{O}$ espectador pode identificar-se com a angústia de Dalva, que, em raros momentos, deixa escapar uma movimentação mais palatável. No final de Doces poderes, o diagnóstico do jornalismo é aparentemente realizado com precisão. Celebra-se o "fracasso" de Bia como uma vitória e a queda da heroína apazigua o espectador porque ela cumpriu seu périplo ostentando a garnacha da justiça: $O$ que importa é o exemplo, a pedagogia moral. O fracasso, no melodrama, também enseja o triunfo da virtude. O herói morre mas deixa o exemplo, dizia Pixerécourt - o mestre dos melodramas teatrais do século 19. 
O gênero não permite as contradições e a discussão profunda das questões, pois basta o exemplo moral e a gratificação. Numa sociedade com tendências a infantilização, ${ }^{1}$ personagens como Bia encontram respaldo pelo altruísmo, encarado como parte da natureza humana. ${ }^{2}$ Isso esclarece, em parte, por que o jornalista é visto no cinema quase sempre como um herói: um sujeito que luta contra as adversidades para reafirmar o compromisso com a verdade baseada em princípios da cultura cristã.

A aproximação de Um céu de estrelas com a tragédia é lembrada porque seus personagens afastam-se do modelo em que se basearam Hector Babenco [Lúcio Flávio, o passageiro da agonia, Carandiru] e Lúcia Murat [Doces Poderes]. Como as explicações são escassas na narrativa, a intenção pedag бgica observada em Lúcio Flavio e Doces poderes, não aparece no filme de Tata Amaral. De acordo com Xavier (1999) "A tragédia como idéia reguladora tem uma virtude, que é a de propiciar uma dramaturgia geradora de interrogações, porque $e$ um espaço que pode gerar paradoxos. É um espaço que pode gerar ruptura com causalidades já assentadas, é um espaço que pode gerar reposição de perguntas que já não pareciam possíveis".

O embate entre Dalva e Vítor vai prosseguir de forma lacônica, sem ancoradouros pontuais para a eclosão de causas e efeitos como na narrativa de feição clássica-melodramática. $\mathrm{O}$ aparecimento da mãe de Dalva, que encarna valores morais para achincalhar Vítor, põe em cena a personagem melodramática. Há um borramento de fronteiras na condução do enredo, mas que rapidamente retorna ao projeto de uma aproximação com elementos da tragédia. ${ }^{3}$ A mãe, que seria a possibilidade de conciliação e apazi-

1. Kehl (1996) traça um panorama da infantilização das massas que se submetem ao poder das elites com base numa vitimização e na esperança de serem sempre amparadas.

2. Kehl (1996, p.216), citando Freud em O mal-estar da civilização, afirma que "se o altruísmo fizesse parte da natureza humana não teria sido necessário se inventar um mandamento para nos convencer a amar o próximo".

3. Williams (2002) entende que Nietzche e Schopenhauer influenciaram George Steiner a decretar a impossibilidade da "experiência trágica nos tempos modernos". Steiner e outros acadêmicoss, segundo Iná Camargo (2002), se incomoda- 
guamento, sucumbe. Os dois personagens crescem depois do interregno melodramático e não há conspirações e entraves externos, até aquele momento, a culpabilizar pelas decisões tomadas.

O filme apresenta Dalva e Vítor como agentes do próprio destino com dificuldades para se desvencilhar das amarras que os encarceram. Além dissso, Um céu de estrelas representa o que Raymond W:illiams (2002) denomina “"tragédia liberal":

No centro da tragédia liberal há uma situação isolada: um homem no ponto culminante de seus poderes e no limite de suas forças, a um só tempo aspirando e sendo derrotado, liberando energias e sendo por elas mesmas destruídas. A estrutura é liberal na ênfase sobre a individualidade que se excede, e trágica no reconhecimento final da derrota ou dos limites que se impõem à vida. (Williams; 2002, p. 119)

Vitor encarna esse personagem trágico. $\mathrm{O}$ filme centra seu foco narrativo nessa idéia do indivíduo e seu ímpeto destrutivo. No cotejo com Doces Poderes, o filme se distancia do enfoque melodramático. A aproximação com elementos da tragédia o expõe a outra indagação diversa daquela lançada sobre o filme de Lúcia Murat.

$\therefore$. Para Williams, o conceito de tragédia está acoplado ao de experiência, pois nele reside o "fundamento trágico por excelência". A atualização do conceito prossegue no cotejo qúe faz entre a tragédia grega, com conjugação dos mitos e o espírito coletivo, e a modernidade, na qual o individuo encontra-se desamparado, isolado:após a queda dos mitos religiosos, de todas as matizes, que the davam farta sustentação simbólica. Essas constatações deveriam reforçar a idéia de que vivemos uma tragédia moderna sem os

vam ao uso inadequado de "trágico", ou seja, não se pode atribuir o termo as catástrofes, acidentes fatais no trânsito urbano, genocídios, etc. Williams vê preconceito e ausência de valorização do processo histórico. Para ele, ao condenar o uso do termo e sua popularização, os "acadêmicos" esquecem de observar a atualizaçăo do conceito e seus novos significados. 
esquivos da academia - segundo Williams, desde Nietzsche há uma desautorização para o uso do termo tragédia para os acontecimentos do mundo moderno. A instituição não deveria rejeitar a nomenclatura "tragédia" para acontecimentos como acidentes, desemprego em massa e catástrofes. As representações das ações humanas deveriam ser historicizadas para absorvermos de fato o legado dos gregos.

Desobrigado da tutela religiosa, o homem moderno adquire mais espaço para a locomoção física e cultural, mas, ao mesmo tempo, pressente a responsabilidade dada pela nova liberdade e vive à beira de uma epidemia depressiva. Adquire-se mais liberdade, entretanto, o contraponto é temer o vazio diante da ausência de tutela patriarcal ou religiosa. Isolado e "livre", o homem moderno reabilita o senso trágico.

Um céu de estrelas tende a esquivar a essa idéia de tragédia moderna. Vítor e Dalva encarnam e representam, em parte, essa estrutura de sentimento ${ }^{4}$ moderna permeada de liberdade, desamparo e derrota. Os personagens trágicos diferem dos melodramáticos, entre outras coisas, porque assumem os desafios que os tornam mais fortes. Abreu (1999) aponta a importância do contato com o trágico, pois, segundo ele, "nos torna mais fortes e nos coloca desafios que devemos enfrentar para conseguirmos chegar à maturidade". Por isso, há pouco espaço para as conciliações ou conspirações externas que vitimizam o herói. A impossibilidade não existe para o personagem trágico. Se a mãe de Dalva é um entrave, Vítor não teme tomar uma decisão: matá-la. Após o extermínio da mãe, os dois dão prosseguimento ao "desencontro" que avança para o impasse absoluto.

4. Segundo Iná Camargo (2002), "estrutura de sentimento" é um termo recorrente ao longo de Tragédia Modema de Raymond Williams. Trata-se de uma expressão cunhada "para se referir a um conteúdo de experiências e de pensamento que, histórico em sua natureza, encontra na formalizaçăo mais específica nas obras de arte, marcando, por exemplo, a estrutura de peças, romances, filmes. Uma das modalidades de sua presença está em traços recorrentes de época, em convençōes de gênero ou em outros dados estilístico-formais que definem o perfil de uma ou de um conjunto de obras. 
As diferenças entre o melodrama e a tragédia são pertinentes, contudo, as ponderações de Williams, em cotejo com a narrativa; fazem sentido. $O$ filme "fecha". os personagens para a história. Os ímpetos de.Vítor provêm de sua personalidade sem ligação com a "história humana". O externo, as contradições da história e os motivos da sua exasperação não são estampados. De acordo com Williams (2002, p. 120), "o que vemos [o que ele denomina tragédia liberal], então, é uma ação geral tornada específica, e não uma ação individual tornada geral".

Por outro lado, o final do filme coloca mais questões: com a entrada em cena do telejornalismo (será o contexto histórico proposto por Williams?), a "tragédia liberal" sucumbe para a entrada do melodrama clássico?

O movimento circular dos dois é quebrado com a interferência externa do telejornalismo e da polícia. O barulho dos tiros faz com que a polícia cerque a casa e, aos poucos, o público, com a "ajuda" da televisão e da polícia, vai contornando a vida privada e forçando uma solução. Dalva coloca a faca no peito dele. Ele, o revólver na testa dela. Lá fora, a jornalista de televisão começa a cobertura do fato. As duas experiências se chocam completamente: dentro do universo doméstico há uma relação privada em compasso de espera; fora, a mídia dissemina uma narrativa dos fatos que não se aplica à verdade do que acontece na casa. $O$ fato interno é denso, envolve pouquíssima alternativa. A jornalista inicia sua intervenção com um discurso deslocado, mas incisivo. Ela não sabe do que se passa, seu relato é confuso e esbarra nos procedimentos mais bási$\cos$ da investigação do fato jornalístico.

O jornalismo de televisão dos anos 90 tende à espetacularização porque as motivações para relatar os fatos deslocaram-se do campo da hegemonia do texto para o campo da imagem clássica, objẹtiva. Isso não quer dizer de um ressentimento pela "submissão" do texto em relação a imagem, e sim o equilíbrio que o encontro das duas formas de nărrar pode ensejar.

A jornalista não quer saber e nem tem fontes suficientes para relatar o que acontece com Dalva e Vítor. Sua intervenção é no sentido de organizar uma narrativa exagerada, espetacular, chocan- 
te, na qual as informações já estão lançadas a priori. Dalva e Vítor, após a morte da velha senhora, ligam a televisão e acompanham a cobertura do cerco. Eles estão ali, na cozinha, impassíveis sem saber o destino, enquanto a televisão e a polícia preparam a invasão. Estão paralisados e acompanham o próprio "fim trágico" como se vissem uma outra ocorrência. É o telejornalismo que passa a explicar para eles e para nós o acontecimento.

O telejornalismo é um dos setores do jornalismo em que o uso da objetividade é apregoado e apologizado. Todavia, é nas coberturas policiais que o conceito é colocado em xeque de forma incisiva, uma vez que o jornalista de televisão faz a reportagem sempre acompanhada de militares. De antemão sua participação está comprometida porque o "outro lado" não será ouvido e sequer será chamado a enunciar seus argumentos. Como a repórter pode anunciar um fato se não possui as mínimas informações? Mas é isso que a repórter enseja: relata um fato para o público sem checar o ocorrido. Sua movimentação diante das câmeras é histérica no sentido de evidenciar a encenação de um fundo falso de notícia: o que está ocorrendo realmente? Ela entrevista o tenente responsável pela ação policial. Mesmo assim, a fonte da notícia é vazia, pois não tem as informações necessárias que poderiam se transformar em notícia. Num gesto espontâneo ela entrevista uma vizinha que informa ser o caso de um sequiestro. Mas quem é o sequiestrador? Ela checa a informação para anunciar um verdadeiro seqüiestro?

O "espetáculo" diante das câmeras torna-se a própria notícia: os gestos efusivos, a respiração ofegante e a narração em ritmo de suspense ganham relevância em detrimento do fato. Ela eleva o suspense quando anuncia que há uma "refém". O espaço interno é superposto pelo externo. O que transcorre no plano privado, vira "espetáculo" no plano externo, público.

O que sobressai é a exaltação da velocidade e do espetáculo proporcionado pelo telejornalismo. Se o filme se fecha no "espaço trágico" até quase o seu final, com a entrada do telejornalismo ele suscita o borramento de fronteiras entre cinema $\mathrm{e}$ a televisão. A construção da notícia na televisão obedece a outro ritmo que prescinde da paciência e da investigação. Em pesquisa 
com a categoria dos jornalistas, Pereira Júnior (2001, p.122) revela que $57,7 \%$ dos entrevistados "considera muito importante os media conseguirem obter informações rapidamente. Só um por cento dos jornalistas afirmou não ter importância nenhuma.”. Essa pesquisa mostra o quanto a velocidade está enraizada na profissão. Dessa forma, os fatos se submetem a lógica da produção jornalística de televisão. Há uma descontextualização do fato e a notícia "verdadeira" passa a ser a elaborada pelo aparato técnico-narrativo, sem ligação efetiva com os acontecimentos. Isso significa que a "imagem" fabricada, por si só, torna-se mais importante do que o fato.

$O$ jornalismo sensacionalista de televisão primeiro espetaculariza o fato, para depois correr em busca da notícia "verdadeira". A manipulação do fato pelo telejornalismo cria, segundo Silva (1999, p. 14), um enfeitiçamento da realidade.

No caso do telejornalismo, esse "enfeitiçamento" torna-se ainda mais grave, pois há o acréscimo da imagem e as sensações emanadas: O jornalista de televisão, nesse caso, não é mais um porta-voz dos fatos, e sim uma espécie de condutor da encenação que infiltra na realidade: É um jornalismo de sensações como atesta Silva (1999, p. 165): "Para o lugar da referência à realidade mediante conceitos entrou a referência através das sensações. Assim ;o jornalismo vai fazer dessa aparente dificuldade da não existência de conceitos claros a priori e da sensação como intermediária da realidade, seu ponto forte e sua força junto ao leitor [espectador]". Não se espera mais do jornalismo de televisão a reportagem do fato, do acontecimento, mas sim a sensação advinda do espetáculo que se edifica:

Em Um céu de estrelas internaliza esse movimento do telejornalismo ao representar a sujeição do espaço diegético do filme ao "espetáculo" da televisão. Na segunda intervenção da jornalista, durante a sua fala, ouve-se um tiro A polícia invade a casa e a câmera do filme é: substituída no espaço fílmico pela câmera da televisão. Não estamos mais vendo o filme pela câmera do narrador onisciente, afastado pela intromissão da televisão, que "rouba" a ação e passa a estabelecer o seu ponto de vista, do fato e do filme. É a câmera que gravava a jornalista, ao vivo, que assume o espaço do cinema, do ponto de vista do diretor. Ao "ver" Dalva com o revólver na mão e 
Vítor, morto, estendido sobre a mesa da cozinha, a câmera da televisão, agora guia de direção no espaço diegético do filme, pára e "toma consciência" da tragédia. Por alguns minutos, no canto esquerdo da tela, está inscrito "ao vivo" e o tempo da ação é congelado. O mundo que estava sendo reportado fora da casa, ao vivo, se depara com outro fato.

O filme de Tata Amaral estanca por um momento o fluxo melodramático do telejornalismo, ao aplacar a sensação com a constatação de que a reportagem enfeitiçava a realidade:

$O$ conceito de enfeitiçamento parece querer significar que o sujeito percebe algo, mas esse algo não corresponde ao ente da realidade (Silva, 1999, p. 161)

Descontextualizada, o filme consegue fazer a critica do telejornalismo, mas, em outro sentido, citado aqui na referência a Raymond Wiliams, ao não historicizar, o submete a idéia de uma "tragédia restrita", oposta a uma noção mais ampla de tragédia.

\section{Bibliografia}

ABREU, Alzira Alves de. A modernização da imprensa (19702000). Rio de Janeiro:

BONASSI, Fernando. $O$ acaso, a tragédia, o espectador e a sombra. Rio de Janeiro: Cinemais, n.15, 1999.

COSTA, Iná Camargo. Prefácio do livro Tragédia moderna de Raymond Wilhams,. São Paulo: Cosac \& Naify, 2002.

BERNARDETH, Jean-Claudel. Cinema e tragédia. Estudos de cinema. São Paulo: PUC-SP, 1999.

PEREIRA Jr. Alfredo Eurico Vizeu. Decidindo o que é notícia. Porto Alegre: Edipucrs, 2001.

KEHL, Maria Rita. A mínima diferença. São Paulo: Imago, 1996.

SILVA, Marconi Oliveira da. $O$ mundo dos fatos e a estrutura da linguagem. Porto Alegre: Edipucrs, 1997. 
XAVIER, Ismail. Cinema e tragédia. Estudos de cinema. São Paulo: PUC-SP, 1999.

WILLIAMS. Raymond. Tragédia moderna. São Paulo: Cosac \& Naify, 2002. 